\title{
Communicating Benefits from Vaccines Beyond Preventing Infectious Diseases
}

\author{
Emma-Pascale Chevalier-Cottin • Hayley Ashbaugh • Nicholas Brooke • \\ Gaetan Gavazzi · Mauricio Santillana · Nansa Burlet · Myint Tin Tin Htar
}

Received: May 21, 2020 / Published online: June 24, 2020

(C) The Author(s) 2020

\begin{abstract}
Despite immunisation being one of the greatest medical success stories of the twentieth century, there is a growing lack of confidence in some vaccines. Improving communication about the direct benefits of vaccination as well as its
\end{abstract}

Digital Features To view digital features for this article go to https://doi.org/10.6084/m9.figshare.12482654.

E.-P. Chevalier-Cottin $(\bowtie)$

Sanofi Pasteur, Lyon, France

e-mail: pascale.cottin@sanofi.com

H. Ashbaugh

Department of Epidemiology, UCLA Fielding School of Public Health, UCLA Fielding School of Public

Health, South, Los Angeles, CA, USA

N. Brooke

The Synergist.org, Brussels, Belgium

G. Gavazzi

Geriatric Clinic, Grenoble-Alpes University

Hospital, GREPI EA, Grenoble-Alpes University,

7408 Grenoble, France

M. Santillana

Harvard Medical School/Boston Children's Hospital, Boston, USA

N. Burlet

Global head Patient Insights Innovation, Sanofi

Pasteur, Lyon, France

M. Tin Tin Htar

Medical Development and Scientific/Clinical

Affairs, Pfizer Inc., Paris, France benefits beyond preventing infectious diseases may help regain this lost confidence. A conference was organised at the Fondation Merieux in France to discuss what benefits could be communicated and how innovative digital initiatives can used for communication. During this meeting, a wide range of indirect benefits of vaccination were discussed. For example, influenza vaccination can reduce hospitalisations and deaths in older persons with diabetes by $45 \%$ and $38 \%$, respectively, but the link between influenza and complications from underlying chronic non-communicable diseases such as diabetes is frequently underestimated. Vaccination can reduce antimicrobial resistance (AMR), which is growing, by reducing the incidence of infectious disease (though direct and indirect or herd protection), by reducing the number of circulating AMR strains, and by reducing the need for antimicrobial use. Disease morbidity and treatment costs in the elderly population are likely to rise substantially, with the ageing global population. Healthy ageing and life-course vaccination approaches can reduce the burden of vaccine-preventable diseases, such as seasonal influenza and pneumococcal diseases, which place a significant burden on individuals and society, while improving quality of life. Novel disease surveillance systems based on information from Internet search engines, mobile phone apps, social media, cloud-based electronic health records, and crowd-sourced systems, contribute to improved 
awareness of disease burden. Examples of the role of new techniques and tools to process data generated by multiple sources, such as artificial intelligence, to support vaccination programmes, such as influenza and dengue, were discussed. The conference participants agreed that continual efforts are needed from all stakeholders to ensure effective, transparent communication of the full benefits and risks of vaccination.

Keywords: Communication; Direct benefits; Indirect benefits; Vaccination; Vaccines

\section{Key Summary Points}

Communication about vaccination benefits often concentrates on direct benefits (disease prevention), but there is a wide range of indirect effects.

Communicating the full benefits of vaccination could help to regain public confidence in vaccines and vaccination.

The meeting participants agreed that continual efforts are needed from all stakeholders to ensure effective, transparent communication of the full benefits and risks of vaccination.

\section{INTRODUCTION}

Vaccination is still, by far, the safest and most effective way of preventing infectious diseases, and is acknowledged to be one of the greatest global health achievements, with an estimated 2-3 million deaths averted every year [1]. Over the last two centuries, vaccination has enabled smallpox to be eradicated, and it has reduced global child mortality rates and prevented countless birth defects and lifelong disabilities, such as paralysis from polio [2].

However, the benefits from vaccines and vaccination programmes go beyond preventing infections. There is a growing body of scientific evidence about indirect benefits, but these benefits and their impact are often underestimated and poorly communicated. They include the reduction of the medical and socioeconomic disease burden and the synergy between vaccination and disease prevalence. The protection offered by many vaccines can be extended, through herd protection, to unvaccinated individuals in the community, including those in vulnerable populations who are either too young to be vaccinated, have waning immune systems (i.e., the elderly), or are immunosuppressed due to medical conditions or treatment. Also, vaccination can prevent the negative impact on quality of life that is observed in some individuals who have suffered from a preventable disease. In addition, veterinary vaccines not only improve animal health but they can also have a positive impact on human infections for certain diseases by reducing the use of antimicrobials in food-producing animals, and thus control the development of antibiotic resistance in pathogens, such as Campylobacter, Salmonella, Escherichia coli and Staphylococcus aureus, that can infect humans $[3,4]$.

Communication on vaccine effectiveness and safety should be proactive, implemented at the early stages of the implementation of vaccination programmes and continued routinely. This communication increase awareness about the overall benefits of vaccines and vaccination programmes, including their indirect benefits as well as their direct benefits. Confidence in vaccines and vaccination programmes has been negatively affected by well-publicised scares about vaccine safety, such as the debunked study linking autism and measles-mumps-rubella (MMR) vaccination [5]. This increasing global and specific vaccine hesitancy needs to be addressed by proactive communication on vaccines and vaccination programmes.

As with any communication, it is important to ensure that the target audience receives and understands the information. New technologies, such as mobile phones, websites and social media could be used to ensure that the communication is accessible. However, it is also necessary to ensure that the information is 
actually received by the target audience, and that it is understandable, in order to help regain and maintain public trust in vaccination and its benefits.

A two-day meeting was organised by the Fondation Mérieux in December 2017 at their conference centre in Veyrier-du-Lac, France, to discuss these issues and illustrate them through examples [6]. This meeting brought together 44 experts from 12 countries who shared their experiences about the full benefits from vaccination, both direct and indirect, and methods for effective communication about vaccine benefits and how innovative digital initiatives could be effectively used in communication.

A medical writer attended the meeting and prepared an outline of this paper based on the presentations and discussion during the meeting. This was completed and validated by the authors who were consenting members of the Scientific Committee, who then worked with the medical writer to develop the complete paper. The conference presentations and discussions are summarised under four main themes:

1. Indirect benefits of vaccines and vaccination.

2. Improving vaccination uptake to increase benefits from vaccination.

3. Disease surveillance and epidemiological forecasting.

4. Public health communication strategies.

This paper reports the presentations and ensuing discussion during the meeting, and we acknowledge that not all aspects of these themes were covered in the meeting. This article is based on previously conducted studies and does not contain any studies with human participants or animals performed by any of the authors.

\section{INDIRECT BENEFITS OF VACCINES AND VACCINATION}

The indirect benefits of vaccines and vaccination are numerous and often underestimated. Examples of some of these benefits are summarised in Fig. 1 and Table 1 [7-20].
Conjugate pneumococcal vaccines (PCV) provide a powerful illustration of numerous indirect benefits. Antimicrobial resistance develops naturally over time, usually through genetic changes, but the misuse and overuse of antibiotics have accelerated this process. As the rate of resistance grows, fewer effective antibiotics are available to treat common infectious diseases which can then become untreatable. Since the introduction of the first PCV vaccine containing antigens from seven pneumococcal strains (PCV7), the incidence of penicillin nonsusceptible disease, particularly due to vaccinetype strains, has decreased, not only in vaccinated children but also in unvaccinated individuals, particularly the elderly [22]. This is thought to be due to a reduction in nasopharyngeal carriage, and thus the presence of fewer pathogens leading to less severe diseases which resulted in fewer antibiotics being prescribed. One study showed a decrease in antibiotic prescriptions of $18 \%(95 \%$ CI 6 ; 38) from 2000 to 2010 for children and adolescents, with no change in adults and an increase of $30 \%$ in the elderly [23]. Other vaccines, such as diphtheria, pertussis, Hib, meningococcal, influenza, measles and varicella, also have the potential to reduce antibiotic use and the development of antimicrobial resistance [10, 24]. The full benefits of PCV vaccines include a reduction in hospital visits for acute otitis media, reduced incidences of community-acquired pneumonia (CAP), invasive pneumococcal disease (IPD), and pleural effusion, CAP- and IPD-associated hospitalisation in vaccinated and unvaccinated populations $[25,26]$. In addition, the incidence of any bacteraemia decreased from $>100 /$ 100,000 children aged 3-36 months in 1998 to $<20 / 100,000$ children in 2014 [27].

It is estimated that about $16 \%$ of human cancers globally are caused by infectious agents, although data from reliable registries in Africa suggests that $30-50 \%$ of cancers could be caused by infectious agents. A number of oncogenic viruses have been identified, and these include human papilloma virus (HPV), hepatitis B and C viruses (HBV, HCV), Epstein-Barr virus (EBV), Human T-Lymphotropic Virus Type 1 (HTLV-1), human herpesvirus-8 (HHV-8) and Merkle cell polyomavirus (MCV) $[28,29]$. Cancer is not a 


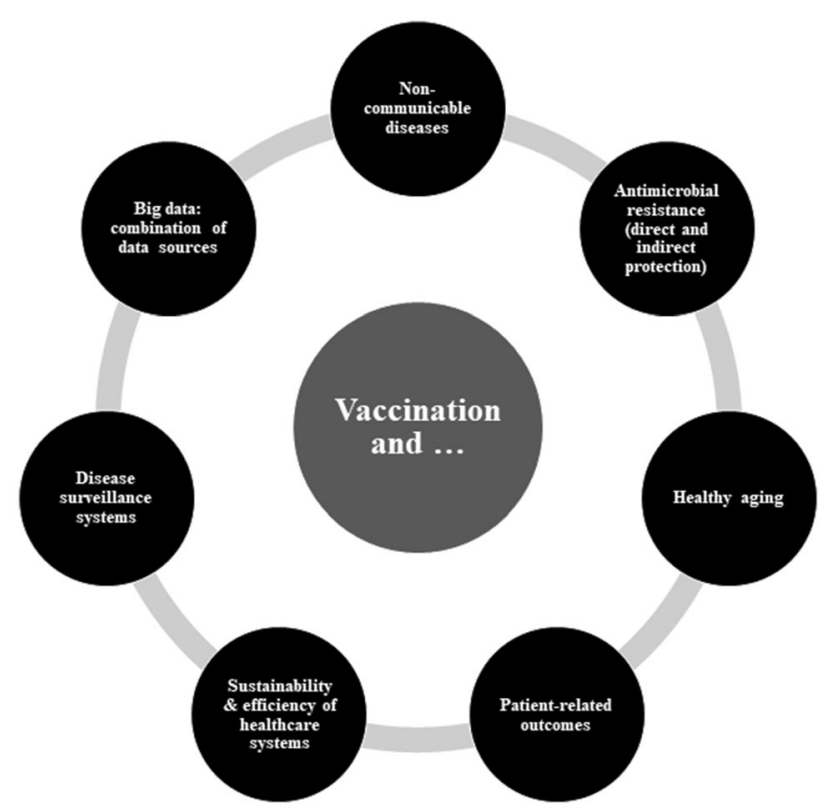

Fig. 1 Examples of benefits from vaccines and vaccinology

primary feature of the disease process and the tumours do not contain replicative virus. However, cancer can occur in chronically infected individuals and, therefore, prevention of the initial infection, which will also prevent chronic infection, will reduce cancer incidence due to oncogenic viruses. Vaccines for HPV have been shown to prevent HPV infections and to reduce the incidence of pre-cancerous lesions. Although vaccines are not currently available for all oncogenic viruses, there is hope that when they do become available and are shown to prevent initial infection, and therefore chronic infection, they will also have an impact on cancer incidence.

Over the past two decades, much progress has been made towards global measles control, as uptake of the first dose of measles-containing vaccine (MCV1) increased worldwide between 2000 and 2017 from 72 to $85 \%$, and measles mortality decreased an estimated 80\% (from 545,174 to 109,638 ) during the same time period [30]. While this reduction in mortality is encouraging, even in a healthy child, infection with measles virus is associated with a short (approximately 1 week) lymphopenia and a more prolonged period of immune suppression $[31,32]$. Some studies suggest that there is a loss of immunological memory due to measles virus' preferential infection of $\mathrm{CD} 150+$ memory lymphocytes and their subsequent depletion $[31,33]$. A recent study in the Netherlands has confirmed that measles virus infection can reduce pre-existing protective antibodies [34]. The association of measles infection with increased morbidity and mortality due to nonmeasles infectious disease has been shown in populations of children from wealthy countries, and this increased mortality rate appears to last for 2-3 years after the infection $[35,36]$.

This potential prolonged immune suppression is particularly important in countries such as the Democratic Republic of the Congo (DRC) where malnutrition, associated with dysfunction of cell-mediated immunity, is widespread and may result in increased measles mortality, relative to wealthy countries [37-39]. A study of 2350 children between 9 and 59 months of age in the DRC showed that children with a reported history of measles infection were more likely to have had a fever in the 2 weeks preceding parental interview (OR: 1.80, 95\% CI $1.25 ; 2.60)$ compared with children who did not have a history of measles [40]. In the same study, receipt of measles vaccination was protective against recent fever (OR: 0.53, 95\% CI 
Table 1 Examples of indirect benefits provided by specific vaccines

\begin{tabular}{|c|c|}
\hline Vaccines & Indirect benefits \\
\hline $\begin{array}{l}\text { Pneumococcal conjugate } \\
\text { vaccines }\end{array}$ & $\begin{array}{l}\text { Prevention of } \\
\text { nasopharyngeal carriage } \\
{[7,8]} \\
\text { Reduction of diseases in } \\
\text { unvaccinated populations } \\
\text { (herd or indirect effect) } \\
\text { [9] } \\
\text { Reduction of antimicrobial } \\
\text { resistance and } \\
\text { antimicrobial use }[10]\end{array}$ \\
\hline $\begin{array}{l}\text { Haemophilus influenzae } \\
\text { type B, meningococcal } \\
\text { disease, measles; viral } \\
\text { vaccines, such as } \\
\text { influenza, respiratory } \\
\text { syncytial virus, and } \\
\text { measles }\end{array}$ & $\begin{array}{l}\text { Reduced antimicrobial use, } \\
\text { including use for } \\
\text { secondary infections, and } \\
\text { reduced antimicrobial } \\
\text { resistance }[11-13] \\
\text { Reducing inappropriate } \\
\text { antibiotic prescriptions } \\
{[14]}\end{array}$ \\
\hline Influenza & $\begin{array}{l}\text { Reduced antimicrobial use } \\
\text { and antimicrobial } \\
\text { resistance }[15] \\
\text { Decrease in cardiovascular } \\
\text { events, i.e. myocardial } \\
\text { infarction, stroke, cardiac } \\
\text { insufficiency [16-18] }\end{array}$ \\
\hline Hepatitis B & $\begin{array}{c}\text { Cirrhosis and liver cancer } \\
\text { (due to prevention of } \\
\text { chronic carriage) }[19]\end{array}$ \\
\hline $\begin{array}{l}\text { Human papilloma virus } \\
\text { (HPV) }\end{array}$ & $\begin{array}{l}\text { HPV-related cancers (due to } \\
\text { prevention of chronic } \\
\text { carriage) in both female } \\
\text { and male }[20] \\
\text { Vertical transmission } \\
\text { (neonatal) }[21]\end{array}$ \\
\hline
\end{tabular}

$0.38 ; 0.73)$, and similar work examining children in the DRC suggests that measles may have a long-term negative impact on pre-existing, vaccine-induced immunity to tetanus [41]. These studies suggest that measles vaccination programmes are important in both resourcepoor and resource-wealthy countries, not only for the prevention of measles infection but also for the indirect prevention of other infectious diseases.

In Libya, the first vaccination programme was set up in the 1960s, and it has been updated constantly and now covers both children and adults. Vaccination, which is enforced by law, is free of charge to everyone, including those living in war zones and displaced persons, and has promoted equity in the country and reduced poverty [42]. This is considered to be the cornerstone of the healthcare system, and public support is crucial for the success of the vaccination programme. The programme has contributed to reductions in infant morbidity and mortality rates, in congenital disease rates, in sequelae from vaccine-preventable diseases, such as permanent disability, and in rates of diseases related to infection, such as cancer. Although it is expensive, the annual return-oninvestment is estimated to be about $12-18 \%$, although the full economic benefits of the improved health of the population continue to be largely underestimated.

Vaccination, as a prevention strategy, should be viewed as part of an age-based approach to health throughout all phases of life [43]. Although many people view vaccination as just a childhood intervention, it is also important for adults and the elderly, the so-called 'lifecourse vaccination' [44]. Vaccination in adults and, in particular, the elderly, goes beyond prevention of infectious diseases. The elderly often have chronic diseases such as diabetes and cardiovascular and renal disease and these conditions can be aggravated by infections, which can require hospitalisation, worsening of chronic diseases and lead to disability and death (Fig. 2) [16-18, 45-47]. Waiting until adults are 'old' before vaccinating can be too late due to immunosenescence, i.e., the ageing of the immune system, leading to poor immune responses [48, 49]. Preventing infections can preserve quality of life in the elderly, and can help prevent catastrophic disability in the elderly population [50]. 


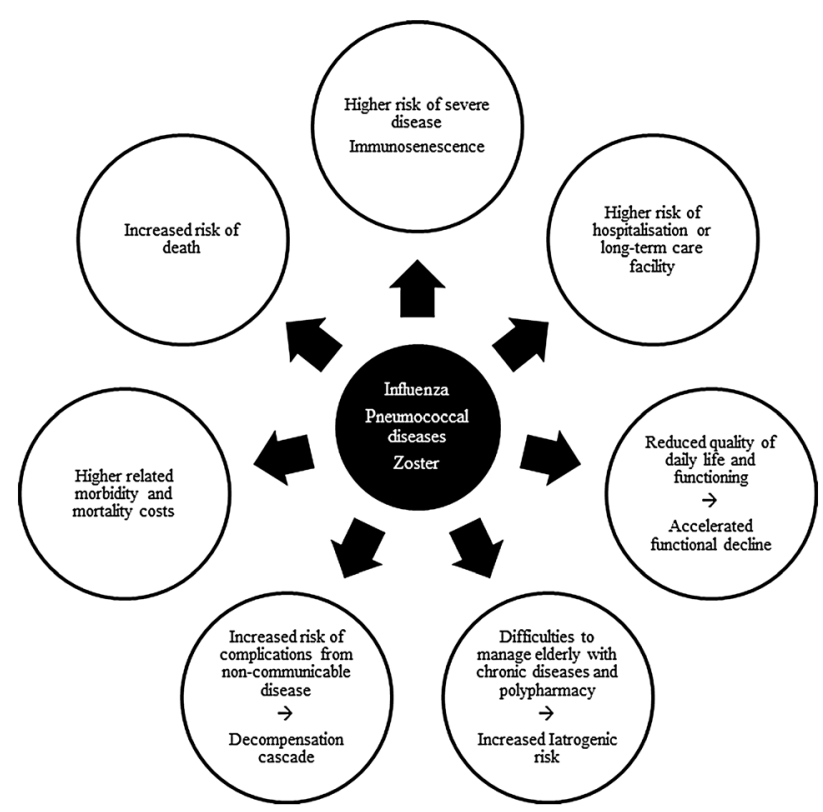

Fig. 2 Impact of influenza, zoster and pneumococcal diseases on the frailty syndrome in the elderly

Indirect benefits from vaccination can be economic. For example, it has been estimated that, for children born in the US during 1994-2013, vaccination will have prevented 322 million illnesses, 21 million hospitalisations and 732,000 premature deaths, resulting in a saving of $\$ 295$ billion in direct medical costs and $\$ 1.38$ trillion in total societal costs [51]. In Finland, it was reported that 195 days of parental work are lost for every 100 influenzainfected children aged $<3$ years [52]. A modelling study for 27 European countries estimated that the overall costs averted for influenza with a $44 \%$ influenza vaccination coverage in eligible populations was $€ 248$ million; if coverage were to be increased to $75 \%$, there would be an additional $€ 190$ million averted [53].

\section{IMPROVING VACCINATION UPTAKE TO INCREASE BENEFITS FROM VACCINATION}

Vaccines by themselves do not prevent infections but vaccination does, and thus it is crucial to reach an optimal vaccine coverage rate to achieve the full benefits of vaccination in a population. The reasons for non-vaccination may vary for different individuals and can also be either for specific vaccines or for vaccination in general, leading to refusal of all vaccines [54]. In the context of growing vaccine hesitancy, constantly changing population dynamic, disease epidemiology and communication channels around the world, developing specific, strategic communication is a crucial element of vaccination policies to ensure high vaccine uptake to enable the full benefits of vaccination to be achieved. This communication should be based on public or audience listening through formal research or monitoring Internet and social media, understanding audience profile, interacting and trust-building [55].

The ADVANCE consortium, a European initiative funded by the Innovative Medicines Initiative, was composed of public and private partners, including regulatory agencies, public health institutions, research institutes and vaccine manufacturers. ADVANCE developed recommendations for strategies for the communication of the benefits and risk of marketed vaccines to inform decision-making [56]. The ADVANCE consortium recommend that a comprehensive communication strategy should be developed, using a multi-stakeholder 
approach, early in any post-marketing vaccine project. They recommend a step-wise approach, with, first, the definition of the goal and objectives of the communication; second, the mapping of stakeholders; third, the development of content and core component such as audience identity, communication channels and message and engagement strategy; and finally, the development of an implementation and monitoring plan. They stress the need for transparency, both for the evidence generation process and the involvement and role of different partners, which is of particular importance when a public-private collaboration is involved [57].

Education of the communication targets and the development of confidence in the source of the information (e.g., vaccine manufacturers, health authorities) are essential for ensuring the effectiveness of the communication. In addition, the communication dissemination route should be adapted to each audience. The vast array of communication tools, ranging from one-to-one conversations with healthcare providers, print media, television and Internet, with the increasing number of social media tools, need to be matched with the information being communicated and the audience being targeted to ensure effective communication.

One example of the importance of communication is the 2014 'Fluad crisis' in Italy [58]. Following the death of three elderly people, two batches of Fluad were recalled and vaccination with Fluad was suspended by the Italian Medicines Agency as a precautionary measure. Following investigation, it was concluded that the batches were not contaminated and the nature of the deaths (cardiovascular) in the elderly people ruled out an infectious cause [59]. However, the disproportionate amount of media coverage given to the decision to suspend vaccination with Fluad, compared with that given to the conclusions of non-association, resulted in a $7 \%$ decrease of influenza vaccination uptake in the elderly and reduced vaccine confidence in the general population $[58,60,61]$. This crisis emphasised the importance of having data on background rates for events, such as death, in the populations targeted by the different vaccines in order to be able to distinguish legitimate safety concerns from events that could have a temporal association with vaccination, particularly for mass vaccination programmes [62]. Negative events, in this case, death, create more 'buzz' than positives ones; in this case, the non-association of vaccination with the deaths. This crisis is one example of how information is readily disseminated via the press and social media and how quickly reports can become 'viral', without having the complete story presented in a balanced manner [63]. Hence, improving communication on vaccines should proactively not only concentrate on safety but should also be accompanied by communication on vaccine benefits, both direct and indirect, with the aim of restoring confidence in vaccination, reducing vaccine hesitancy and improving vaccination uptake.

\section{DISEASE SURVEILLANCE AND EPIDEMIOLOGICAL FORECASTING}

Disease surveillance and epidemiological forecasting systems are improving with advances in Internet tools. These are important, as they can provide estimates of disease activity and vaccine effectiveness in near-real time. Examples of such systems include HealthMap, which provides content that is aggregated from diverse, freely available information sources covering a broad range of emerging infectious diseases $[64,65]$. Another example is Break Dengue, which has been set up by a non-profit organisation to connect different initiatives addressing the issue of dengue around the world, so that together they can have a bigger impact [66]. Break Dengue uses 'crowd surveillance' as one of its data sources. Both healthcare professionals and members of the public can report dengue cases via the Break Dengue website. The system does not collect symptoms or propose treatment, it only asks several questions following a decisions tree to understand the context of the visitor, including if the diagnosis has been confirmed by a doctor for a scenario involving reporting cases. At the end of the decision tree, tailored advice is offered to 
inform the visitor and help reduce the spread of the disease. This crowd surveillance, coupled with data from internet search engines and social media reports of new cases, provides high-quality, close to real-time, disease surveillance [67-69]. Although the website does not promote vaccination, it connects interdependent stakeholders, and raises disease awareness and the understanding that vaccination is the solution for prevention. Close to real-time surveillance integrated with stakeholder-specific user interfaces have the potential to connect interdependent stakeholders, such as health authorities, physicians, patients and other stakeholders in the field, and help improve all aspects of immunisation, from prevention and surveillance to vaccination campaigns. It is planned to develop similar systems for other diseases in the future.

In addition, the data collected by this system can be used to feed into quantitative models of epidemiological prediction which can be used to support public health decision-making. In 2014, the American Centers for Disease Control and Prevention (CDC) started the Epidemic Prediction Initiative (EPI) that aims to improve the science and usability of epidemic forecasts by facilitating open forecasting projects with specific public health objectives [70]. Since January 2016, influenza forecasts from participating teams in real time have been published on their website. Although these forecasts have consistently outperformed historical expectations, they are actively developing and testing new models. In Europe, epidemiological data are collected and owned by each country and are generally not publicly available. Surveillance strategies are exploring the combination of digital data through ensemble modelling and further participative approaches with all stakeholders, looking at increasing forecasting performance and actionability of surveillance data. Hence, other approaches for sharing real-time data, particularly vaccine effectiveness and post-marketing safety surveillance, are being explored in projects such as ADVANCE, VAC4EU and DRIVE in Europe [71-73].

During the ADVANCE project, the importance of reinforcing credibility of vaccine-related information and building sustainable confidence in vaccines and vaccination for all stakeholders were emphasised [57]. Organisations such as CDC and WHO provide on-line vaccine information services that are accessible by the general public as well as by healthcare professionals [1, 74]. Transparency and independence are crucial characteristics for any information source for ensuring public trust.

\section{PUBLIC HEALTH COMMUNICATION STRATEGIES}

The challenges for the delivery and communication of information about vaccines and vaccination to parents and other members of the lay public include having the right information at the right time and providing reliable information to improve the perception of the benefits and safety of vaccines and vaccination. One way of doing this could be to expand the role of the different vaccine providers (e.g. pharmacists/pharmacy assistants, nurses), who will need access to the information that they will communicate, and also training to allow them to deliver the information effectively. One example of this is the use of SMS messages to remind parents and other individuals that their vaccination is due, which was shown to improve the completion of HPV vaccination series $[75,76]$. Educational messages that foster vaccine health literacy can also be transmitted via SMS by healthcare professionals.

It has been reported that school settings offer a unique opportunity to reach important target groups with comprehensive health information and to promote positive behaviour change for children and their families [77]. In some settings, the current efforts to promote parental vaccine acceptance are insufficient, as shown by below-target vaccination uptake rates. One solution could be to look at a longer-term strategy in which children, who are the future generations of parents, are taught to be more aware of all the benefits of vaccines and vaccination, and therefore more likely to accept vaccination and be less prone to react negatively to vaccine safety scares. This could be achieved by targeting school children to create an understanding of vaccines and vaccination 
at an early age and, thereby, encourage them to accept vaccination when they are adults. Ideally, education about vaccines and vaccination could become an integral part of school curricular, in the same way as other health topics, such as preventive behaviours. A game-based module on vaccines, designed to provide experienced-based learning, which is more effective than passive learning with second-hand knowledge, has been developed. In a game, it is possible to convert theoretical knowledge into practical knowledge, i.e. learning by doing. Learning games are ideal for schools because they engage and motivate students, which are the most important factors when learning. Also, games create an environment in which individuals can develop relevant skills and knowledge to enable them to react in an evidenceinformed manner and to test their knowledge without fear of failure. Classroom Games is a gamified educational platform, but it is not a computer game, as the students spend most of their time solving tasks in an analogue environment and not on a computer. The WHO European Regional Office is developing and pilot-testing a game-based education module on immunisation and vaccination for school children aged $10-11$ years, with the aim of promoting durable positive behavioural changes in children and their families, and building population resilience against vaccine safety scares in Europe.

\section{DISCUSSION AND CONCLUSIONS}

The participants at the workshop all agreed that it is important to continue to share experiences about communicating the whole range of vaccine and vaccination benefits to increase their impact and to improve vaccination uptake. How this information is obtained must be clearly and transparently explained to guarantee its credibility. In addition to communicating the benefits of vaccines and vaccination, it is important that information about any safety issues are rapidly communicated to show that all organisations, both public and private, are actively collecting safety data using validated scientific methods. The overall aim of communicating this information is to promote informed decision-making using evidencebased benefit/risk ratios at all levels, including health authorities, with the goal of improving vaccination uptake, and therefore all citizens' health. This is increasingly important, as we have moved away from childhood vaccination towards the paradigm of life-course vaccination with the aim of not just preventing infantile morbidity and mortality but also promoting healthy ageing.

While communication needs to be transversal, we must ensure that correct and pertinent information is delivered to the target audience in a format that they can readily access, understand, and use at the right time. Advances in communication technologies should be used to facilitate this and to enable timely deliverable of the right information to the right audience. Alert systems, such as SMS, which can be used to remind individuals about their next vaccination, as well as provide information about vaccines and vaccination, can contribute to the timely delivery of information.

Education of all target audiences will be essential to ensure that the communicated information can be correctly used. In addition to educating healthcare professionals about vaccines and vaccination, they must also be trained in communication, as they remain an important source of information for many individuals. Education of the general public could start in schools. Although this requires a long-term investment, it will produce members of the public who are knowledgeable about the importance of vaccines, vaccination, and the full benefits of vaccines, and who will be equipped to respond in an informed manner to vaccine safety scares. We should also educate journalists about the importance of providing balanced reporting of vaccine safety concerns. They need to report not only on vaccine safety scares as they occur but they also need to report the findings from the ensuing investigations so as to provide the full story to the public. The Fluad incident in Italy and the debunked link between MMR vaccination and autism, mentioned earlier, are examples in which reporting on the initial scare far outweighed reporting on the results from the subsequent investigations, 
which led to loss of public confidence and important reductions in vaccination uptake.

This conference report highlights the wide spectrum of indirect benefits of vaccination beyond the well-known direct benefits in vaccinated populations. It also emphasises the importance of transparent and effective communication strategies and the need to build mutual trust and understanding between all public and private vaccine organisations and the lay public. We need to improve our understanding of the various social behaviours of parents and other individuals that influence decision-making processes for vaccines and vaccination. We also need to improve our understanding of healthcare professionals' motivation to provide impartial, credible information about vaccination and its full benefits, and to build on this to train them to communicate to, and install an effective dialogue with, parents and other individuals. The conference participants called for continual efforts from all stakeholders to ensure effective, transparent communication of the full benefits and risks of vaccines and vaccination with the aim of improving health for all individuals. To achieve this, all stakeholders, including the lay public, must continue to dialogue and collaborate.

\section{ACKNOWLEDGEMENTS}

The authors would like to thank the speakers, in particular Robert Cohen, Michael Johansson, Louise Letley, Siff Malue Nielsen, David Sinclair, Melissa Stockwell, Alberto Tozzi for their input in earlier versions of this paper, and the participants at the meeting for their active involvement in discussions during the meeting. The views and information presented are those of the authors and do not represent the official position of the U.S. Army Medical Center of Excellence, the U.S. Army Training and Doctrine Command, or the Departments of Army, Department of Defense, or U.S. Government.

Funding. The meeting was funded by the Fondation Mérieux who received an unrestricted grant from Sanofi Pasture. Funding for the Rapid Service Fees incurred was provided by Sanofi Pasteur.

Medical Writing and Editorial Assistance. Medical writing and editorial assistance for this manuscript was provided by Margaret Haugh, MediCom Consult, Villeurbanne, France, and was funded by Sanofi Pasteur.

Authorship. All named authors meet the International Committee of Medical Journal Editors (ICMJE) criteria for authorship for this article, take responsibility for the integrity of the work as a whole, and have given their approval for this version to be published.

Disclosures. Emma-Pascale Chevalier-Cottin and Nansa Burlet are employed by Sanofi Pasteur. Myint Tin Tin Htar is employed by Pfizer. Hayley Ashbaugh, Nicholas Brooke, Gaetan Gavazzi and Mauricio Santillana declare that they have no conflict of interest.

Compliance with Ethics Guidelines. This article is based on previously conducted studies and does not contain any studies with human participants or animals performed by any of the authors.

Open Access. This article is licensed under a Creative Commons Attribution-NonCommercial 4.0 International License, which permits any non-commercial use, sharing, adaptation, distribution and reproduction in any medium or format, as long as you give appropriate credit to the original author(s) and the source, provide a link to the Creative Commons licence, and indicate if changes were made. The images or other third party material in this article are included in the article's Creative Commons licence, unless indicated otherwise in a credit line to the material. If material is not included in the article's Creative Commons licence and your intended use is not permitted by statutory regulation or exceeds the permitted use, you will need to obtain permission directly from the copyright holder. To view a copy of this licence, visit http://creativecommons.org/licenses/by$\mathrm{nc} / 4.0 /$. 


\section{REFERENCES}

1. World Health Organisation. Health topics: Vaccines 2019. https://www.who.int/topics/vaccines/en/. Accessed 9 Nov 2019.

2. Andre FE, Booy R, Bock HL, Clemens J, Datta SK, John TJ, et al. Vaccination greatly reduces disease, disability, death and inequity worldwide. Bull World Health Organ. 2008;86:140-6.

3. Newell DG, Koopmans M, Verhoef L, Duizer E, Aidara-Kane A, Sprong $\mathrm{H}$, et al. Food-borne diseases-the challenges of 20 years ago still persist while new ones continue to emerge. Int J Food Microbiol. 2010;139(Suppl 1):S3-15.

4. Lekshmi M, Ammini P, Kumar S, Varela MF. The food production environment and the development of antimicrobial resistance in human pathogens of animal origin. Microorganisms. 2017;5:11.

5. Taylor LE, Swerdfeger AL, Eslick GD. Vaccines are not associated with autism: an evidence-based meta-analysis of case-control and cohort studies. Vaccine. 2014;32:3623-9.

6. Foundation Merieux. Event: Communication of vaccine benefits beyond the infection prevented. Les Pensieres Center for Global Health, Veyrier du Lac, France. 4-6 December 20172017 Available from: https://www.fondation-merieux.org/en/ events/communication-of-vaccine-benefitsbeyond-the-infection-prevented/. Accessed 1 Apr 2020.

7. Tin Htar TM, van Den Biggelaar AHJ, Sings H, Ferreira G, Moffatt M, Hall-Murray C, et al. The impact of routine childhood immunization with highervalent pneumococcal conjugate vaccines on antimicrobial-resistant pneumococcal diseases and carriage: a systematic literature review. Expert Rev Vacc. 2019;18:1069-89.

8. Weil-Olivier C, van der Linden M, de Schutter I, Dagan R, Mantovani L. Prevention of pneumococcal diseases in the post-seven valent vaccine era: a European perspective. BMC Infect Dis. 2012;12:207.

9. Griffin MR, Zhu Y, Moore MR, Whitney CG, Grijalva CGUS. hospitalizations for pneumonia after a decade of pneumococcal vaccination. N Engl J Med. 2013;369:155-63.

10. Dagan R. Impact of pneumococcal conjugate vaccine on infections caused by antibiotic-resistant Streptococcus pneumoniae. Clin Microbiol Infect. 2009;15(Suppl 3):16-20.
11. Clift C, Salisbury DM. Enhancing the role of vaccines in combatting antimicrobial resistance. Vaccine. 2017;35:6591-3.

12. Ginsburg AS, Klugman KP. Vaccination to reduce antimicrobial resistance. Lancet Glob Health. 2017;5:e1176-7.

13. Jansen KU, Anderson AS. The role of vaccines in fighting antimicrobial resistance (AMR). Hum Vaccin Immunother. 2018;14:2142-9.

14. Fleming-Dutra KE, Hersh AL, Shapiro DJ, Bartoces M, Enns EA, File TM Jr, et al. Prevalence of Inappropriate Antibiotic Prescriptions Among US Ambulatory Care Visits, 2010-2011. J Am Med Assoc. 2016;315:1864-73.

15. Esposito S, Principi N. Influenza vaccination and prevention of antimicrobial resistance. Expert Rev Vaccines. 2018;17:881-8.

16. Nichol KL, Nordin JD, Nelson DB, Mullooly JP, Hak E. Effectiveness of influenza vaccine in the community-dwelling elderly. N Engl J Med. 2007;357: 1373-81.

17. Warren-Gash C, Blackburn R, Whitaker H, McMenamin J, Hayward AC. Laboratory-confirmed respiratory infections as triggers for acute myocardial infarction and stroke: a self-controlled case series analysis of national linked datasets from Scotland. Eur Respir J. 2018;51:1701794.

18. Wong CM, Chan KP, Hedley AJ, Peiris JS. Influenzaassociated mortality in Hong Kong. Clin Infect Dis. 2004;39:1611-7.

19. Chang MS, Nguyen MH. Epidemiology of hepatitis $\mathrm{B}$ and the role of vaccination. Best Pract Res Clin Gastroenterol. 2017;31:239-47.

20. Bresse X, Adam M, Largeron N, Roze S, Marty R. A comparative analysis of the epidemiological impact and disease cost-savings of HPV vaccines in France. Hum Vaccin Immunother. 2013;9:823-33.

21. Lee SM, Park JS, Norwitz ER, Koo JN, Oh IH, Park JW, et al. Risk of vertical transmission of human papillomavirus throughout pregnancy: a prospective study. PLoS ONE. 2013;8:e66368-e.

22. Kyaw MH, Lynfield R, Schaffner W, Craig AS, Hadler J, Reingold A, et al. Effect of introduction of the pneumococcal conjugate vaccine on drug-resistant Streptococcus pneumoniae. N Engl J Med. 2006;354:1455-63.

23. Lee GC, Reveles KR, Attridge RT, Lawson KA, Mansi IA, Lewis JS 2nd, et al. Outpatient antibiotic prescribing in the United States: 2000 to 2010. BMC Med. 2014;12:96. 
24. Andreano E, D'Oro U, Rappuoli R, Finco O. Vaccine Evolution and Its Application to Fight Modern Threats. Front Immunol. 2019;10:1722.

25. Lau WC, Murray M, El-Turki A, Saxena S, Ladhani S, Long $\mathrm{P}$, et al. Impact of pneumococcal conjugate vaccines on childhood otitis media in the United Kingdom. Vaccine. 2015;33:5072-9.

26. Levy C, Biscardi S, Dommergues MA, Dubos F, Hees $\mathrm{L}$, Levieux $\mathrm{K}$, et al. Impact of PCV13 on community-acquired pneumonia by C-reactive protein and procalcitonin levels in children. Vaccine. 2017;35: 5058-64.

27. Greenhow TL, Hung YY, Herz A. Bacteremia in Children 3 to 36 Months Old After Introduction of Conjugated Pneumococcal Vaccines. Pediatrics. 2017;139.

28. Gaglia MM, Munger K. More than just oncogenes: mechanisms of tumorigenesis by human viruses. Curr Opin Virol. 2018;32:48-59.

29. Krump NA, You J. Molecular mechanisms of viral oncogenesis in humans. Nat Rev Microbiol. 2018;16:684-98.

30. Dabbagh A, Laws RL, Steulet C, Dumolard L, Mulders MN, Kretsinger K, et al. Progress toward regional measles elimination-Worldwide, 2000-2017. Morb Mortal Wkly Rep. 2018;67:1323-9.

31. de Vries RD, McQuaid S, van Amerongen G, Yuksel $\mathrm{S}$, Verburgh RJ, Osterhaus $\mathrm{AD}$, et al. Measles immune suppression: lessons from the macaque model. PLoS Pathog. 2012;8:e1002885.

32. Laksono BM, de Vries RD, McQuaid S, Duprex WP, de Swart RL. Measles virus host invasion and pathogenesis. Viruses. 2016;8:210.

33. de Swart RL, Ludlow M, de Witte L, Yanagi Y, van Amerongen G, McQuaid S, et al. Predominant infection of CD150 + lymphocytes and dendritic cells during measles virus infection of macaques. PLoS Pathog. 2007;3:e178.

34. Mina MJ, Kula T, Leng Y, Li M, de Vries RD, Knip M, et al. Measles virus infection diminishes preexisting antibodies that offer protection from other pathogens. Science. 2019;366:599-606.

35. Gadroen K, Dodd CN, Masclee GMC, de Ridder MAJ, Weibel D, Mina MJ, et al. Impact and longevity of measles-associated immune suppression: a matched cohort study using data from the THIN general practice database in the UK. BMJ Open. 2018;8:e021465.

36. Mina MJ, Metcalf CJ, de Swart RL, Osterhaus AD, Grenfell BT. Long-term measles-induced immunomodulation increases overall childhood infectious disease mortality. Science. 2015;348: 694-9.

37. Belamarich PR. Measles and malnutrition. Pediatr Rev. 1998;19:70-1.

38. Carney JM, Warner MS, Borut T, Byrne W, Ament $\mathrm{M}$, Cherry JD, et al. Cell-mediated immune defects and infection. A study of malnourished hospitalized children. Am J Dis Child. 1980;134:824-7.

39. Ministère du Plan et Suivi de la Mise en œuvre de la Révolution de la Modernité (MPSMRM), Ministère de la Santé Publique (MSP), ICF International. Demographic and Health Survey in the Democratic Republic of Congo 2013-2014: Executive Summary Report. [Enquête Démographique et de Santé en République Démocratique du Congo 2013-2014: Rapport de synthèse.]. Rockville, Maryland, USA: MPSMRM, MSP et ICF International.; 2014.

40. Ashbaugh HR, Cherry JD, Hoff NA, Doshi RH, Alfonso VH, Gadoth A, et al. Association of previous measles infection with markers of acute infectious disease among 9- to 59-month-old children in the Democratic Republic of the Congo. J Pediatric Infect Dis Soc. 2019;8:531-8.

41. Ashbaugh H, Cherry JD, Gerber S, Higgins SG, Gadoth A, Alfonso VH, et al. Reported history of measles and long-term Impact on antibody to tetanus in children 6-59 months of age receiving DTP in the Democratic Republic of Congo. Open Forum Infect Dis. 2017;4:S323-S.

42. UNICEF. Joint statement: Libya launches a national vaccination campaign against measles, rubella and polio 2018. https://www.unicef.org/mena/pressreleases/joint-statement-libya-launches-nationalvaccination-campaign-against-measles-rubella. Accessed 2 Apr 2020.

43. Supporting Active Ageing Through Immunisation (SAATI) Partnership. Adult vaccination-a key component of healthy ageing 2013. https://ilcuk. org.uk/wp-content/uploads/2018/11/Adultvaccination_a-key-component-of-health-ageing. pdf. Accessed 2 Apr 2020.

44. Philip RK, Attwell K, Breuer T, Di Pasquale A, Lopalco PL. Life-course immunization as a gateway to health. Expert Rev Vaccines. 2018;17:851-64.

45. Doherty TM, Connolly MP, Del Giudice G, Flamaing J, Goronzy JJ, Grubeck-Loebenstein B, et al. Vaccination programs for older adults in an era of demographic change. Eur Geriatr Med. 2018;9: 289-300. 
46. McElhaney JE, Gavazzi G, Flamaing J, Petermans J. The role of vaccination in successful independent ageing. Eur Geriatr Med. 2016;7:171-5.

47. Wong CM, Yang L, Chan E, Chan KH, Hedley AJ, Peiris JS. Influenza-associated hospitalisation. Hong Kong Med J. 2009;15(Suppl 9):35-7.

48. Haq K, McElhaney JE. Immunosenescence: influenza vaccination and the elderly. Curr Opin Immunol. 2014;29:38-42.

49. Schmader KE, Johnson GR, Saddier P, Ciarleglio M, Wang WW, Zhang JH, et al. Effect of a zoster vaccine on herpes zoster-related interference with functional status and health-related quality-of-life measures in older adults. J Am Geriatr Soc. 2010;58: 1634-41.

50. Andrew MK, Bowles SK, Pawelec G, Haynes L, Kuchel GA, McNeil SA, et al. Influenza vaccination in older adults: recent innovations and practical applications. Drugs Aging. 2019;36:29-37.

51. Whitney CG, Zhou F, Singleton J, Schuchat A. Benefits from immunization during the vaccines for children program era-United States, 1994-2013. Morb Mortal Wkly Rep. 2014;63:352-5.

52. Heikkinen T, Tsolia M, Finn A. Vaccination of healthy children against seasonal influenza: a European perspective. Pediatr Infect Dis J. 2013;32: 881-8.

53. Preaud E, Durand L, Macabeo B, Farkas N, Sloesen B, Palache A, et al. Annual public health and economic benefits of seasonal influenza vaccination: a European estimate. BMC Public Health. 2014;14: 813.

54. Attwell K, Dube E, Gagneur A, Omer SB, Suggs LS, Thomson A. Vaccine acceptance: science, policy, and practice in a 'post-fact' world. Vaccine. 2019;37:677-82.

55. Bahri P, Castillon Melero M. Listen to the public and fulfil their information interests-translating vaccine communication research findings into guidance for regulators. Br J Clin Pharmacol. 2018;84:1696-705.

56. Bahri P, Rago L. CIOMS guide to vaccine safety communication-executive summary. Vaccine. 2019;37:401-8.

57. Torcel-Pagnon L, Bauchau V, Mahy P, Tin Htar HM, van der Sande M, Mahe C, et al. Guidance for the governance of public-private collaborations in vaccine post-marketing settings in Europe. Vaccine. 2019;37:3278-89.
58. Signorelli C, Odone A, Conversano M, Bonanni P. Deaths after Fluad flu vaccine and the epidemic of panic in Italy. BMJ. 2015;350:h116.

59. European Medicines Agency. No evidence that Fluad vaccine caused deaths in Italy 2014. https:// www.ema.europa.eu/documents/press-release/noevidence-fluad-vaccine-caused-deaths-italy_en.pdf. Accessed 2 Feb 2020.

60. Levi M, Sinisgalli E, Lorini C, Santomauro F, Chellini M, Bonanni P. The, "Fluad Case" in Italy: could it have been dealt differently? Hum Vacc Immunother. 2016;13:379-84.

61. Ministero della Salute. Influenza: vaccination coverage [Dati coperture vaccinali] 2019. http://www. salute.gov.it/portale/influenza/ dettaglioContenutiInfluenza.jsp?lingua= italiano\&id $=679 \&$ area $=$ influenza\&menu=vuoto. Accessed 2 Feb 2020.

62. Black S, Eskola J, Siegrist CA, Halsey N, MacDonald $\mathrm{N}$, Law B, et al. Importance of background rates of disease in assessment of vaccine safety during mass immunisation with pandemic H1N1 influenza vaccines. Lancet. 2009;374:2115-22.

63. Odone A, Chiesa V, Ciorba V, Cella P, Pasquarella C, Signorelli C. Influenza and immunization: a quantitative study of media coverage in the season of the $<<$ Fluad case $>>$. Epidemiol Prev. 2015;39: $139-45$.

64. HealthMap 2020. http://www.HealthMap.org/. Accessed 2 Apr 2020.

65. Brownstein JS, Freifeld CC, Reis BY, Mandl KD. Surveillance Sans Frontieres: internet-based emerging infectious disease intelligence and the HealthMap project. PLoS Med. 2008;5:e151.

66. Break Dengue 2018. https://www.BreakDengue. org/. Accessed 2 Apr 2020.

67. Lu FS, Hattab MW, Clemente CL, Biggerstaff M, Santillana M. Improved state-level influenza nowcasting in the United States leveraging Internetbased data and network approaches. Nat Commun. 2019;10:147.

68. Santillana M, Nguyen AT, Dredze M, Paul MJ, Nsoesie EO, Brownstein JS. Combining Search, Social Media, and Traditional Data Sources to Improve Influenza Surveillance. PLoS Comput Biol. 2015;11:e1004513.

69. Yang S, Kou SC, Lu F, Brownstein JS, Brooke N, Santillana M. Advances in using Internet searches to track dengue. PLoS Comput Biol. 2017;13: e1005607. 
70. Epidemic Prediction Initiative (EPI) 2016. https:// predict.cdc.gov/. Accessed 2 Apr 2020.

71. ADVANCE-Accelerated development of vaccine benefit-risk collaboration in Europe 2016. http:// www.advance-vaccines.eu/. Accessed 2 Apr 2020.

72. VAC4EU: VAccine monitoring Collaboration for Europe 2019. https://vac4eu.org/. Accessed 2 Apr 2020.

73. DRIVE-Development of Robust and Innovative Vaccine Effectiveness 2020. https://www.drive-eu. org/. Accessed 2 Apr 2020.

74. Centers for Disease Control and Prevention. Vaccines and immunizations 2020. https://www.cdc. gov/vaccines/index.html. Accessed 2 Apr 2020.
75. Matheson EC, Derouin A, Gagliano M, Thompson JA, Blood-Siegfried J. Increasing HPV vaccination series completion rates via text message reminders. J Pediatr Health Care. 2014;28:e35-9.

76. Rand CM, Vincelli P, Goldstein NP, Blumkin A, Szilagyi PG. Effects of phone and text message reminders on completion of the human papillomavirus vaccine series. J Adolesc Health. 2017;60: 113-9.

77. Carolan K, Verran J, Amos M, Crossley M, Redfern J, Whitton N, et al. SimFection: a digital resource for vaccination education. J Biol Educ. 2019;53: 225-34. 